\title{
Hydraulic Simulation Analysis of Sonic Drilling Hydraulic Vibration Head
}

\author{
Shan Fan ${ }^{1}$, Zeping Chen $^{2}$ \\ ${ }^{1}$ Department of mechanical and electrical engineering, Wenhua College, 430074 Wuhan, China \\ ${ }^{2}$ Chongqing Research Institute of China Coal Technology and Engineering Group, 400039 Chongqing, China
}

\begin{abstract}
The hydraulic vibration head is the core component of sonic drilling rig, and the performance of its hydraulic system influences the technology of sonic drilling directly. The structure and hydraulic system of the hydraulic vibration head are designed, and the AMESim model of the hydraulic system is established in the paper. The hydraulic vibration system is simulated and analyzed to find out the influence rule of vibration frequency on the system performance. The results show that the larger the vibration frequency $f$ is, the smaller the amplitude $\mathbf{H}$ is, and the displacement response of the vibrating piston approximates the sine curve. The velocity and acceleration of the vibrating piston accordingly increased, and the exciting force $\mathbf{F}$ of the vibrating piston increased significantly.
\end{abstract}

\section{Introduction}

In recent years, some achievements have been made in the independent development of Sonic drilling rig in China, and the vibrator is the core key component. There is a developing trend of mechanical vibrator towards full hydraulic vibrator (hydraulic vibrator head). Hydraulic vibrator is the core part of sonic drilling rig, can generate up to $185 \mathrm{HZ}$ high frequency vibration power. With low speed rotation and downward pressure of $100 \sim 200 \mathrm{rpm}$, the drill stem and drill bit can be rapidly drilled[1]. Through the rotation of eccentric wheel, high frequency sinusoidal vibration power is generated, which drives the drill pipe to conduct high frequency vibration. When the frequency of the eccentric wheel is consistent with the longitudinal resonance frequency of the drill pipe, the drill pipe resonates. Resonance can realize the maximization of energy transfer, which enables the drill to quickly cut into the soil layer, so the drilling efficiency is very high[2]. Based on the importance of hydraulic vibration head to sonic drilling, the structure of hydraulic vibration head is designed in the paper. And the influence of vibration frequency on the working performance of hydraulic vibrating head was studied by hydraulic simulation experiment.

\section{Structure design and principle of hydraulic vibration head}

\subsection{Working principle of hydraulic vibrating head}

The function of hydraulic vibrating head is similar to that of hydraulic rock drill. The main difference is in the structure and the distribution mode. The rotary axial flow type vibrator is adopted in the hydraulic vibration head of sonic drilling. Through the rotary motion of the rotating valve, the axial forced flow distribution is carried out, so that the vibrating piston reciprocates at high speed. It is easier to obtain a higher vibration frequency in this way. In terms of structure, the oil distribution gear is removed and the valve core of the rotary valve is used for oil distribution. High-pressure oil can be delivered to the upper and lower cavity of the hydraulic cylinder alternately. In this way, the seismic performance is better and the structure is simple. Because of the frequency control function of the rotary valve, the rotary valve is also commonly referred to as the hydraulic frequency control valve. Using ac servo motor to drive the hydraulic frequency control valve can control the output frequency of the hydraulic frequency control valve accurately. The overall structural design of the hydraulic vibration head is shown in fig.1.

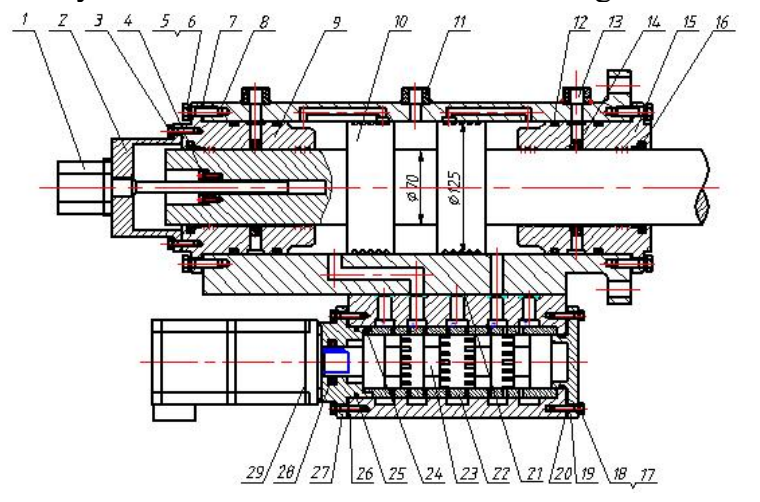

1-displacement sensor; 2-stent; 3, 4, 5-screw; 6-spring washer; 7-adjust the gasket; 8-cylinder body; 9-front end cover; 10piston; 11-oil outlet joint;12-sealing ring; 13-hydrostatic oil 
outlet joint; 14-small hole throttling device; 15 -rear end cover; 16-Stratford; 17-screw; 18- spring washer; 19 -valve rear end cover; 20-adjust the gasket; 21 -sealing ring; 22- valve sleeve; 23 - valve core. 24-cylinder pin;25-sealing ring; 26 - the body; 27 -front end cover of rotary valve; 28 -oil seal; 29 -motor

Fig.1. Structure Diagram of Hydraulic Vibration Head.

The hydraulic vibration head mainly consists of valve core 7, valve sleeve 2 and cylinder body 5 , and its working principle is shown in figure 2 . On the oil valve 7 , there are three inlet and outlet tank shoulder pads, each with 12 oil groove. In the same shoulder, the adjacent two oil groove of the central Angle is $30^{\circ}$. In neighbouring shoulder, tank is mutual dislocation, and the dislocation of the Angle of $15^{\circ}$. The opening of the oil groove under the first shoulder and the middle shoulder is the same. The opening position of the oil groove on the third shoulder and the middle shoulder is the same. When the servo motor drives the hydraulic frequency control valve core 7 to rotate at a constant speed at a certain speed, the high pressure oil enters the upper and lower cavity of the hydraulic vibration cylinder alternately under the distribution of inlet and outlet tank 3 , and drives the vibration piston 9 to conduct periodic reciprocating motion.

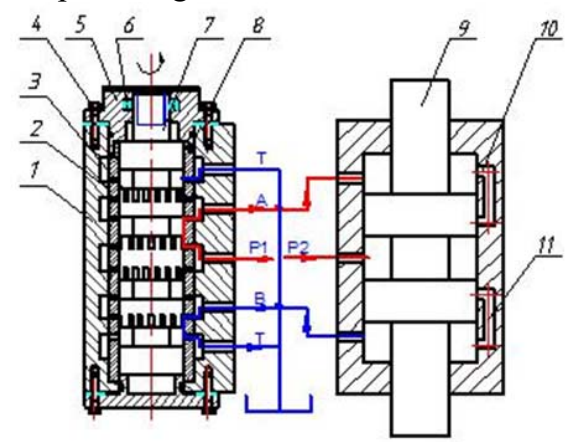

(a) Schematic Diagram of Piston Stroke

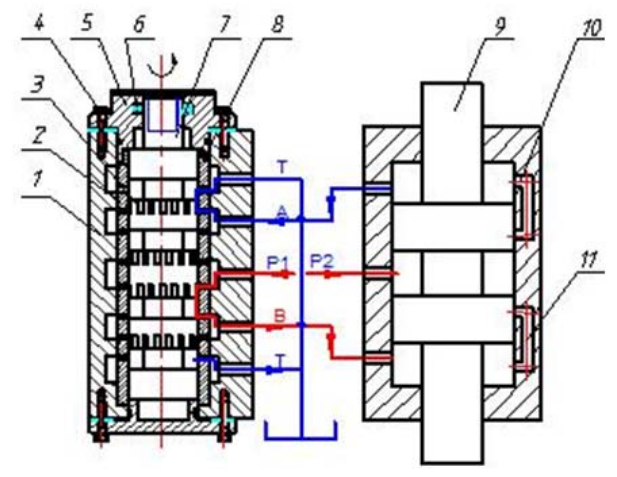

(b) Schematic Diagram of Piston Return Stroke 1-the body; 2-valve sleeve; 3 -oil inlet and outlet channel holes; 4-screw; 5-front cover; 6-sealing ring; 7-valve core. 8-cylinder pin; 9-vibrating piston; 10-upper offset tank; 11-lower offset tank

Fig. 2. Working Principle Diagram of Hydraulic Vibrating Head.

Fig.2 (a) is the schematic diagram of piston stroke. When the valve core of hydraulic frequency regulating valve is in the position shown in fig.2 (a), $P$ communicates with A, B communicates with T. High- pressure oil enters the upper cavity of the hydraulic vibration cylinder, and the piston goes down rapidly.

Fig. 2 (b) is the piston return principle diagram. When the valve core of the hydraulic frequency regulating valve is in the position shown in fig.2 (a), $P$ communicates with $\mathrm{B}$, A communicates with T. Highpressure oil enters the upper cavity of the hydraulic vibration cylinder, and the piston goes up rapidly[3].

From the above analysis, it can be seen that when the servo motor drives the continuous rotation of valve core 7, the high-pressure oil P1 is transferred alternately to the upper and lower cavity of the hydraulic vibration cylinder through the oil groove 3 on valve core 7 , so as to achieve high-frequency excitation.

\section{$2.23 \mathrm{~d}$ modeling of hydraulic vibration head}

Using Solidworks software, the hydraulic vibration head is modeled and assembled in three dimensions, as shown in fig. 3 .

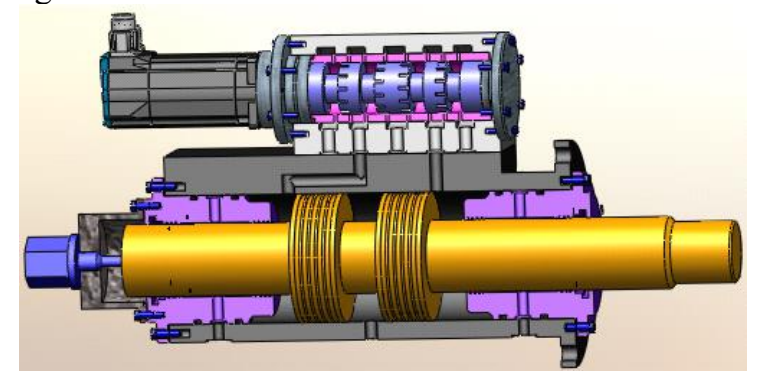

Fig. 3. 3d Assembly Drawing of Hydraulic Vibrating Head.

\section{Hydraulic system and simulation analysis}

\subsection{Design and modeling of hydraulic system}

Based on the structural design of sonic drilling hydraulic vibration head, the hydraulic system of hydraulic vibration head is designed, as shown in fig. 4 .

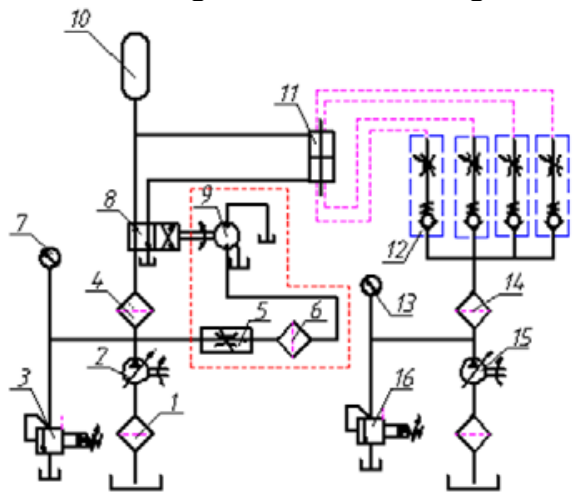

1-oil filter; 2-variable pump; 3-pilot overflow alve; 4 - refined oil filter; 5-speed regulating valve; 6-refined oil filter; 7pressure gauges; 8-rotary hydraulic frequency regulating valve; 9-variable hydraulic motor; 10-energy accumulator; 11vibration cylinder; 12-hydrostatic bearing module; 13pressure gauges; 14-refined oil filter; 15-variable pump; 16overflow valve diagram 
Fig.4. Hydraulic System Schematic Diagram of Hydraulic Vibrating Head.

According to the theory of hydraulic drive and control, the simulation model of the hydraulic vibration system is established by using AMEsim software, and the dynamic performance of the hydraulic vibration system is simulated and analyzed. The simulation model is shown in figure 5 , which mainly consists of variable pump 2, overflow valve 4, hydraulic frequency regulating valve 9 and hydraulic vibration cylinder 10 . Except the hydraulic frequency regulating valve 9 and the hydraulic vibration cylinder 10 are modeled by using HCD, other conventional models are selected for modeling, and each component parameter of the simulation model is set according to the actual situation.

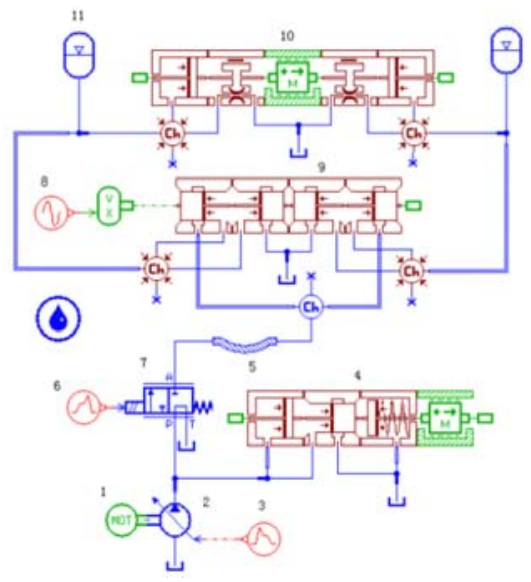

1 - oil filter; 2 - variable pump; 3- pilot overflow valve; 4 refined oil filter; 5- speed regulating valve; 6-refined oil filter; 7-pressure gauges; 8-rotary hydraulic frequency regulating valve; 9-variable hydraulic motor; 10-energy accumulator; 11vibration cylinder; 12-hydrostatic bearing module; 13- pressure gauges; 14- refined oil filter; 15-variable pump; 16-overflow valve diagram

Fig. 5. Hydraulic Vibration System Simulation Model.

As shown in Fig. 5, hydraulic pump 2 supplies oil to the left side of the vibration system through the reversing valve 7 , while the right side is connected to the fuel tank. The displacement of variable pump 2 is given by the control signal of variable pump 3. The pressure oil is forced to flow through the hydraulic frequency regulating valve 9 , which is sent to the upper and lower cavity of the vibration cylinder 10 alternately. The frequency of the hydraulic frequency regulating valve, namely the vibration frequency of the hydraulic vibration system, is set by controlling signal 8 of the hydraulic frequency regulating valve. The system pressure is determined by the overflow valve 4 and is set by the spring pressure of the overflow valve. The pressure of the system is related to the vibration force of the vibration cylinder [4-6].

\subsection{Simulation analysis of hydraulic system}

By setting up the main parameters of the hydraulic vibration cylinder, the hydraulic frequency control valve and the driving signal as well as other main components parameters, the hydraulic vibration head is simulated and analyzed. In the paper, only analyzed the variation and influence of vibration frequency $f$ on amplitude, velocity, acceleration and excitation force of hydraulic vibration system[7-8].

In the hydraulic vibration system, the frequency of the hydraulic frequency regulating valve determines the frequency of the hydraulic vibration cylinder. The vibration mass $m$ was set as $70 \mathrm{~kg}$, the pressure of the vibration system was $15 \mathrm{MPa}$, and the displacement of the variable pump was $70 \mathrm{cc} / \mathrm{r}$. The input frequency signals of $10 \mathrm{HZ}, 50 \mathrm{HZ}, 100 \mathrm{HZ}, 150 \mathrm{HZ}$ and $200 \mathrm{HZ}$ are respectively set. The influence of the change of input frequency on the amplitude, velocity, acceleration and excitation force of the vibration piston by the vibration system is shown in figure 6 .

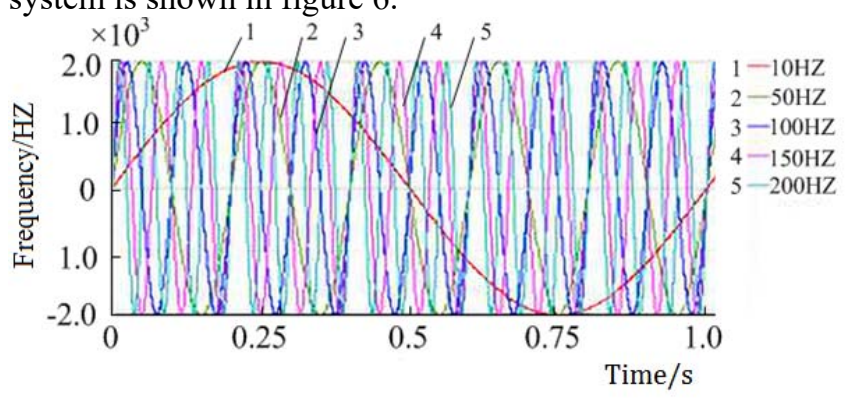

(a) Input Sinusoidal Frequency Signal

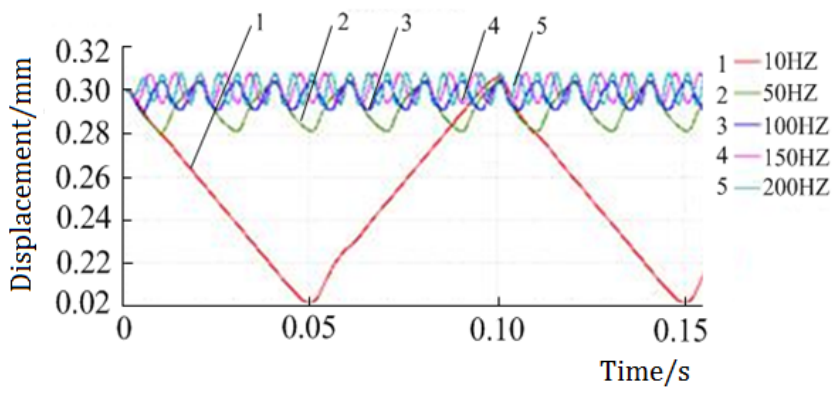

(b) Influence of Different Frequencies on Piston Displacement

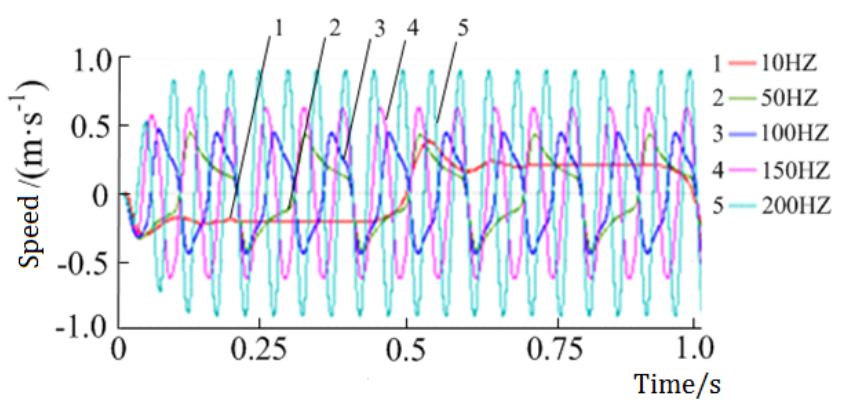

(c) Effects of Different Frequencies on Piston Speed

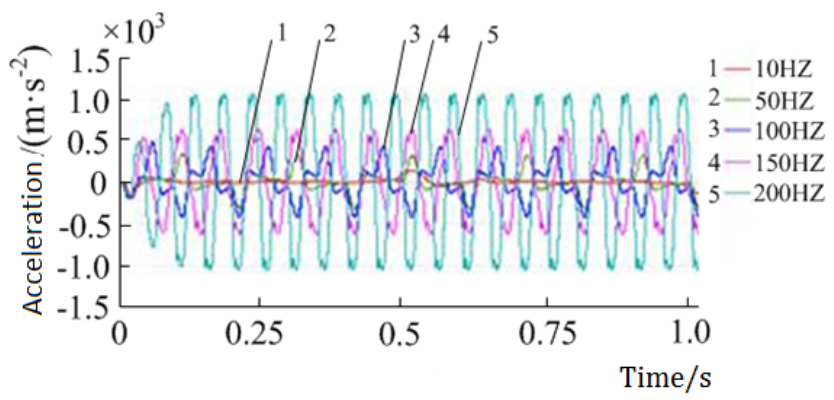

(d) Effects of Different Frequencies on Piston Acceleration 


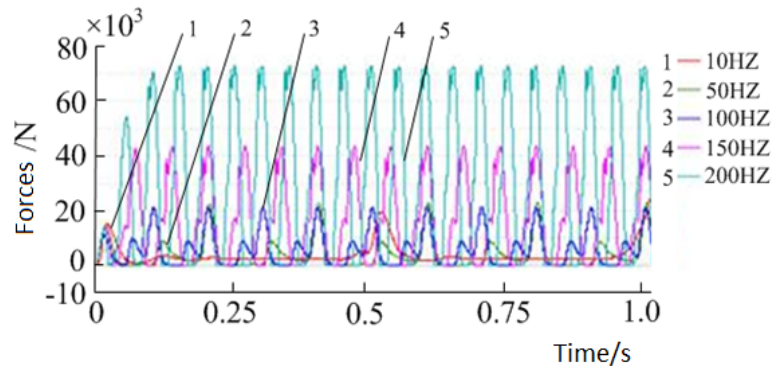

(e) Effects of Different Frequencies on Piston Excitation Forces

Fig. 6. Influence of Different Frequencies on Various Parameters of Hydraulic Vibration System.

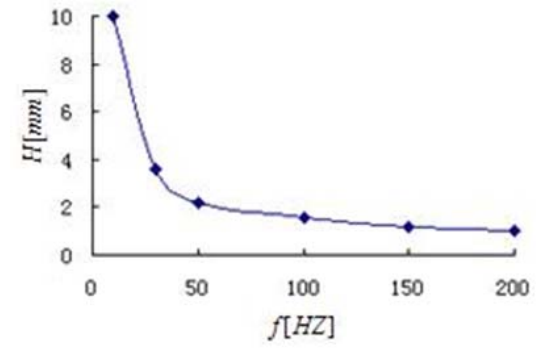

Fig. 7. Diagram of the Relationship between Vibration Frequency and Amplitude.

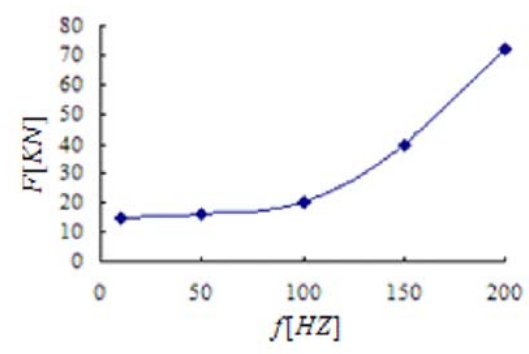

Fig. 8. Diagram of the Relationship between Vibration Frequency and Excitation force.

Fig.6 (a) shows the sinusoidal excitation signals loaded into the system, respectively $10 \mathrm{HZ}, 50 \mathrm{HZ}$, $100 \mathrm{HZ}, 150 \mathrm{HZ}$, and $200 \mathrm{hz}$.

Fig. 6 (b) shows the effect of different frequency $f$ on the displacement of the vibrating piston. The numerical relation between the frequency and the amplitude in Fig.6 (b) is used. The curve was fitted to obtain the fitting curve of vibration frequency and amplitude when the vibration mass $m$ was $70 \mathrm{~kg}$, the pressure of the vibration system was $15 \mathrm{MPa}$, and the displacement of variable pump was $70 \mathrm{cc} / \mathrm{r}$, as shown in Fig. 7.

As shown in Fig.6 (b) and Fig.7, when the frequency of the frequency regulating valve is $10 \mathrm{HZ}$, the amplitude of the vibrating piston can reach $10 \mathrm{~mm}$, and the displacement response curve of the vibrating piston is triangular waveform. When the frequency of the frequency regulating valve is $200 \mathrm{HZ}$, the amplitude of the vibrating piston is $1 \mathrm{~mm}$, and the displacement response curve of the vibrating piston is approximately sinusoidal. When the vibration frequency is small, the vibration amplitude of the piston is relatively large. When the vibration frequency reaches over $100 \mathrm{HZ}$, the amplitude is not much different. It shows that although the amplitude decreases with the increase of vibration frequency, the amplitude decreases rapidly at the low frequency stage and slowly at the high frequency stage.[9-10]

Fig.6(c) and Fig.6(d) show the influence of different frequency $f$ on the velocity and acceleration of the vibrating piston. As the vibration frequency increases, the speed and acceleration of the vibrating piston will increase, with the maximum speed up to $1 \mathrm{~m} / \mathrm{s}$ and the maximum acceleration up to $1000 \mathrm{~m} / \mathrm{s}^{2}$.

Fig.6(e) shows the effect of different excitation frequencies on excitation force $\mathbf{F}$. The numerical relation between the frequency and the excitation force in Fig. 6 (e) is fitted by a curve. The fitting curve diagram of vibration frequency and excitation force when the vibration mass $m$ is $70 \mathrm{~kg}$, the pressure of the vibration system is $15 \mathrm{MPa}$, and the displacement of the variable pump is $70 \mathrm{cc} / \mathrm{r}$ is obtained, as shown in Fig. 8 .

As can be seen from Fig.5 (e) and Fig.7, the excitation force obtained by the piston increases rapidly with the increase of vibration frequency $f$. This shows that, with the same vibration mass $m$, pressure $p$ of the vibration system and oil supply $\boldsymbol{Q}$ of the variable pump, the excitation force $\mathbf{F}$ increases rapidly with the increase of vibration frequency $\mathbf{F}$ [11-12].

In conclusion, it can be concluded that as the vibration frequency $f$ increases, the amplitude $\mathbf{H}$ decreases, and the displacement response of the vibrating piston is similar to the sine curve, the velocity and acceleration of the vibrating piston will increase correspondingly, and the exciting force $\mathbf{F}$ of the vibrating piston will increase significantly.

\section{Conclusion}

In this paper, the structure design and $3 \mathrm{~d}$ modeling of the hydraulic vibration head are carried out, and the hydraulic system design and simulation analysis of the hydraulic vibration head are completed. Through the simulation experiment of AMEsim software, the influence rule of vibration frequency on the performance of hydraulic system is verified. The simulation results obtained are basically consistent with the theoretical analysis. The main vibration parameters related meet the design requirements, indicating that the design of hydraulic vibration system is reasonable. In the next step, other simulation experiments will be carried out with the help of AMEsim software, such as vibration quality, system pressure, oil supply flow and other important parameters on the performance of hydraulic vibration system.

\section{References}

1. Y.Wang, B.L. Liu, Q.Zhou et al. Design and Study for Hydraulic System of Sonic Vibration Driller. Machine Tool \& Hydraulics, 40, 23(2012)

2. C.Li, D.S. SHAN, D.H. ZHAO et al. Modeling and Simulation Research of Hydraulic Vibration System 
Based on AMESim. Machine Tool \& Hydraulics, 43.7(2015).

3. J.Nel. Sonic drilling-environmentally friendly alternative.Geo-Drilling International,5(2002).

4. Y. ZHANG.Analysis on the Structure Principle of Sonic Drilling Vibrator. Exploration Engineering (Rock \& Soil Drilling and Tunneling), 37.7(2010) .

5. Z.j. YIN, Y.X. HU.Dynamic simulation of impact mechanism of hydraulic rock drill based on AMESim. Mining \& Processing Equipment,12 (2011).

6. X.Y.Shen, M.Zhao. Effect of the Seal Force on Nonlinear Dynamics and Stability of the Rotorbearing-seal System. J VIB CONTROL,15(2009).

7. A. Nancy. The Origins of Sonic. GeoDrilling International, 128(2006).

8. R. ROUSSY. The Development of Sonic Drilling
Technology. GeoDrilling International,10(2002).

9. X.Zhou, X.C.Zhu, L.Li. Application of Constant Power Control Technology in HydraulicD rill.Machine Tool \& Hydraulics, 8(2007).

10. L.C.Yu, J.An.Shong, L.J.Shong.Design of hydraulic system for 65 thorizontally directional drilling machine. Chinese Hydraulics \& Pneumatics, 10(2012).

11. CH.He, Y.L.Dong, Q.Li, G.L.Dong. Design for Load Simulation System of Anti-aircraft Gun Servo System Based on Hydraulic Motor. Machine Tool \& Hydraulics, 10(2011).

12. Y.Fei,T.Chen, SH.Jiang. Hydraulic system design of large-tonnage horizontal Direction drilling machine. Chinese Hydraulics \& Pneumatics,2(2011). 